\title{
Metaplastic breast carcinoma: series of cases and literature review
}

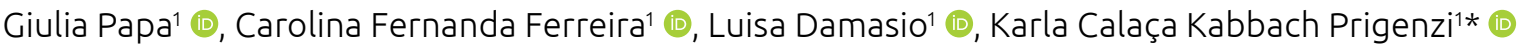

\section{ABSTRACT}

Introduction: Metaplastic breast carcinoma is a heterogeneous group of infrequent invasive carcinomas with aggressive behavior. It presents differentiation from the neoplastic ductal epithelium to squamous and/or sarcomatous mesenchymal component, through the epithelial-mesenchymal transition process, and may present morphology of epithelioid and fusiform cells, with possible cartilage, bone, lipomatous, fibromatous, smooth muscle or skeletal muscle differentiation, among others. Most of the cases present the triple-negative immunohistochemical profile. Objective: To report three cases of metaplastic carcinomas, with an emphasis on clinical and pathological aspects, in addition to conducting a literature review on this topic. Methods: The three cases were registered in the internal search system for reference services in breast pathology in São Paulo, between 2012 and 2019. For literature review, the keywords metaplastic carcinoma, breast, cancer, review, breast cancer subtype and pathological and clinical outcomes were used in PubMed. We found 154 articles, of which 42 were selected for full reading, based on the abstract and established inclusion criteria. After this initial selection, these articles were read and reviewed; nine articles that did not meet the inclusion criteria were excluded. Discussion: Three cases of metaplastic carcinoma with similar immunohistochemical characteristics have been reported. The first case is that of a 40-year-old patient with the diagnosis of metaplastic carcinoma producing a chondroid matrix with liposarcomatous and osteosarcomatous differentiation. The second case is that of a 50-year-old patient who presented with the final diagnosis for a fusocellular metaplastic carcinoma with lymph node metastasis. Finally, the third case described is that of a 59-year-old patient, who presented metaplastic carcinoma with chondroid differentiation. Conclusion: Metaplastic carcinoma is a rare and aggressive type of breast cancer, in which most of the patients have shorter survival and worse prognosis in relation to the other subtypes. More studies are needed in order to determine a gold standard treatment for this disease.

KEYWORDS: triple negative breast neoplasms; breast; neoplasms; review; neoplasms by histological type; treatment outcome.

\section{INTRODUCTION}

Metaplastic breast carcinoma is a heterogeneous group of rare invasive carcinomas with an aggressive profile, which represent approximately $0.2 \%-1 \%$ of malignant breast tumors ${ }^{1}$. This tumor is characterized by the differentiation of the neoplastic ductal epithelium into squamous and/or sarcomatous mesenchymal components, and may present a varied cellular morphology of epithelioid and spindle cell patterns or with specific differentiation for some mesenchymal lineage ${ }^{2,3}$. Its clinical presentation is similar to that of invasive breast carcinomas of no special type (NST), the former invasive ductal carcinoma, and to benign breast lesions, which makes its radiological diagnosis challenging. Metaplastic carcinomas present at diagnosis in more advanced stages. Association with microcalcifications is not common in this type of tumor, except for cases with ductal carcinoma in situ and/or bone differentiation. Several studies indicate that metaplastic breast carcinoma is negative for estrogen receptor (ER), progesterone receptor (RP), and human epidermal growth factor - receptor 2 (HER2) on immunohistochemical examination, which leads to a common generalization of these tumors as triple-negative breast cancer. However, its clinical behavior is different from other tumors included in this same group ${ }^{1,4}$. Thus, even though most metaplastic breast carcinomas have a triple-negative phenotype, as do some NST, the clinical outcomes of both are different, with metaplastic carcinomas mostly having a worse prognosis ${ }^{1,4}$. Furthermore, when comparing the two types of tumors, metaplastic breast carcinoma metastases occur in more distant locations, such as the brain and lung, with a lower incidence of regional lymph node metastasis 5 .

Clinically, most cases manifest as a palpable nodule, and the characterization of the lesion may be possible both by ultrasound and mammography ${ }^{1,6}$. Macroscopically, they may appear as

${ }^{1}$ Faculdade de Ciências Médicas de Santos, Fundação Lusíada - Santos (SP), Brazil.

*Corresponding author: karlakabbach@hotmail.com

Conflict of interests: nothing to declare.

Received on: 03/15/2021 - Accepted on: 06/09/2021. 
well-circumscribed or indistinct-appearing masses with irregular edges. Nielsen et al. suggest that metaplastic breast carcinoma may appear as benign circumscribed, round, or oval masses on mammography; lobular, circumscribed and solid with posterior echogenicity on ultrasound; or even with T2 hyperintensity on magnetic resonance images ${ }^{7}$.

\section{OBJECTIVES}

The main objective of this work was to report three cases of metaplastic carcinomas, with emphasis on clinical and pathological aspects. As a secondary objective, we propose to review the literature on this topic.

\section{METHODS}

A retrospective search of cases with a diagnosis of metaplastic breast carcinoma was carried out, in an internal search system of a reference service in breast pathology in São Paulo, between 2012 and 2019. For this search, we selected, in the field of biological material, only surgical resections of breast, and, in the diagnostic field, the term metaplastic carcinoma of the breast. Three cases were found with such a diagnosis, which are detailed below. As this is a case report study, the research is exempt from the free and informed consent, as only data collection was carried out from medical records and reports of imaging and pathological examinations, not involving any intervention in patients.

To review the literature, the keywords metaplastic carcinoma, breast, cancer, review, breast cancer subtype, and pathological and clinical outcomes were used to search in PubMed. A total of 154 articles were found, of which 42 were selected for full reading based on the abstract and inclusion criteria. Articles in English were included, which were case reports referring to the diagnosis under study or those that performed a literature review or systematic review on the topic, including demographic, imaging, anatomopathological, immunohistochemical, molecular, and differential diagnosis data. After this initial selection, this literature was read and reviewed, and nine articles that did not meet the inclusion criteria were excluded (five described with greater emphasis another histological subtype of breast cancer, two were in Mandarin, and two in French), totaling 33 reviewed articles. Books from the World Health Organization (WHO) and national data from the National Cancer Institute (Instituto Nacional de Câncer - INCA) were also used as bibliographical references and supporting literature.

\section{CASE REPORT}

\section{Case 1}

A 40-year-old female patient presented with a rapidly growing nodule in her left breast for five months. Mammography showed a nodule at the intersection of the left upper quadrants, measuring $7.5 \mathrm{~cm}$, with irregular contours and partially defined limits, classified as BI-RADS 4 (Figure 1). Ultrasound showed a hypoechoic nodule, with lobulated contours, measuring 4.8 x 3.2 x $0.6 \mathrm{~cm}$ (Figure 2). Core needle biopsy was performed, with a diagnosis of malignant epithelial-myoepithelial neoplasia. The patient underwent total mastectomy. Macroscopically, a nodule with well-defined borders, lobulated contours and firm consistency was observed. Histological sections showed poorly differentiated malignant neoplasm, forming solid blocks composed of epithelioid cells, with vesicular nuclei, little evident nucleoli and numerous atypical mitotic figures (Figure 3). It was also observed basophilic chondroid matrix and foci of background osteoid matrix. There were foci with lipoblasts
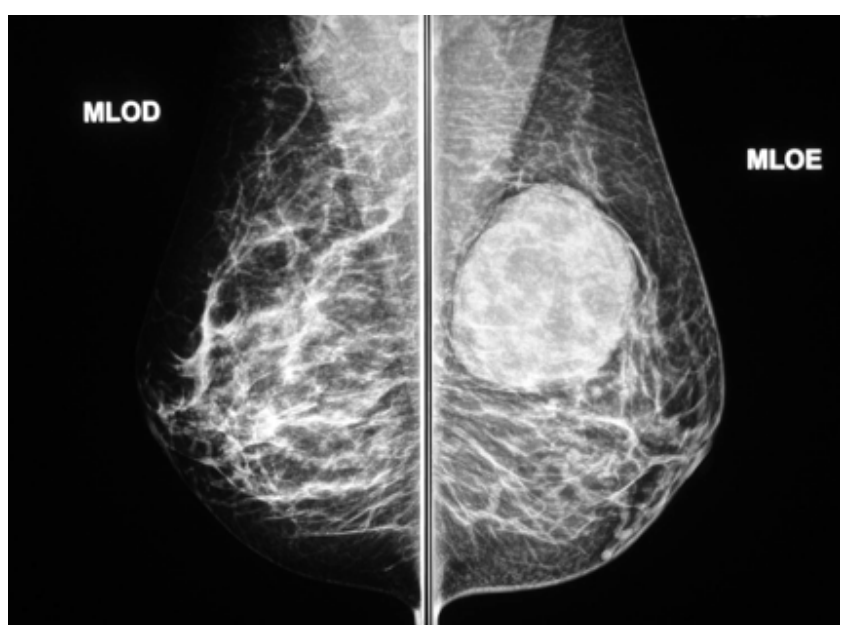

MLOD: right nipple; MLOE: left nipple.

Figure 1. Case 1: mammography shows a nodule at the intersection of the upper left quadrants, with irregular outlines, partially defined limits, BI-RADS 4.

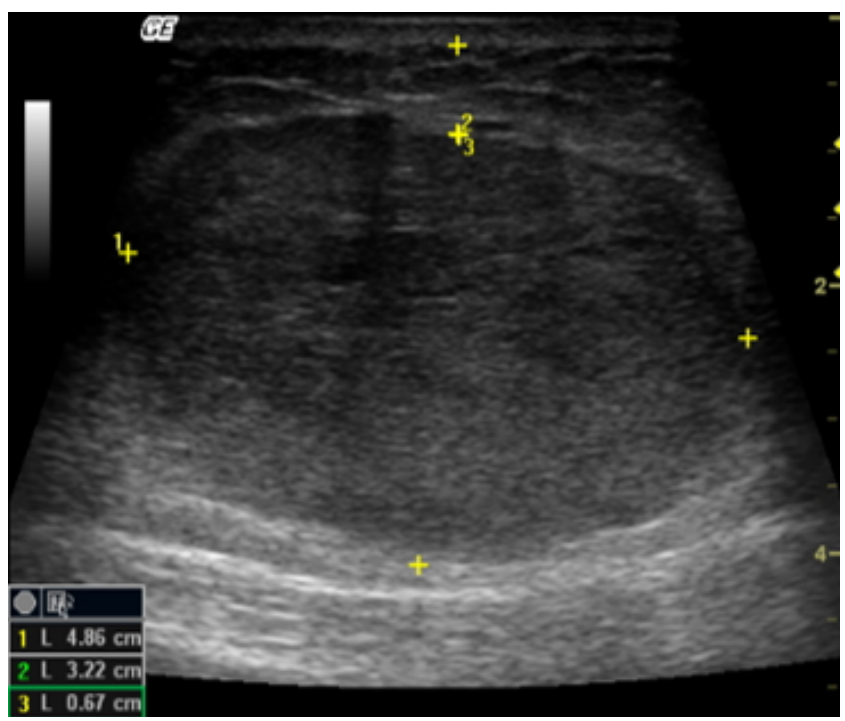

Figure 2. Case 1: ultrasonography shows a circumscribed, oval nodule, parallel to the skin. 
and osteoclast-like multinucleated giant cells. The immunohistochemical study showed a triple-negative profile associated with immunoexpression of cytokeratin 7 (CK 7), p63, S100, EGFR, cytokeratin 5/6 (CK 5/6), vimentin and high cell proliferation index evaluated by Ki67, being the immunomorphological aspects compatible with the diagnosis of metaplastic carcinoma producing chondroid matrix, with liposarcomatous and osteosarcomatous differentiation. Axillary dissection was also performed, and no lymph node metastases were detected.

\section{Case 2}

A 50-year-old female patient presented with a well-delimited nodule in the right breast, classified according to the mammography as BI-RADS 5. A core needle biopsy was performed, with a diagnosis of malignant spindle cell neoplasm, suggestive of sarcoma. The patient then underwent a total mastectomy. Macroscopically, there was a $3.9 \mathrm{~cm}$ nodule, well delimited. Microscopically, malignant neoplastic proliferation was evidenced, predominantly composed of spindle-shaped cells, arranged in elongated, sometimes intersecting, bundles, in addition to a smaller component of epithelioid cells. Nuclei had vesicular loose chromatin, faint nucleoli, and numerous mitotic figures (Figure 4). The immunohistochemical examination revealed negativity for hormone receptors and HER2, with a high rate of cell proliferation at Ki-67, in addition to positivity for pancytokeratin (AE1/AE3), cytokeratin 7 (CK7), cytokeratin 5/6 (CK 5/6), cytokeratin 14 (CK14), smooth muscle actin, vimetin, S100, 34BE12, and EGFR, which concluded that it was a malignant neoplasm with epithelial and mesenchymal differentiation, compatible with the diagnosis of metaplastic breast carcinoma of the fusocellular type. Biopsy of the axillary sentinel and parasentinel lymph nodes showed the presence of macrometastasis in two of the three identified lymph nodes, with the largest focus measuring $15 \mathrm{~mm}$.

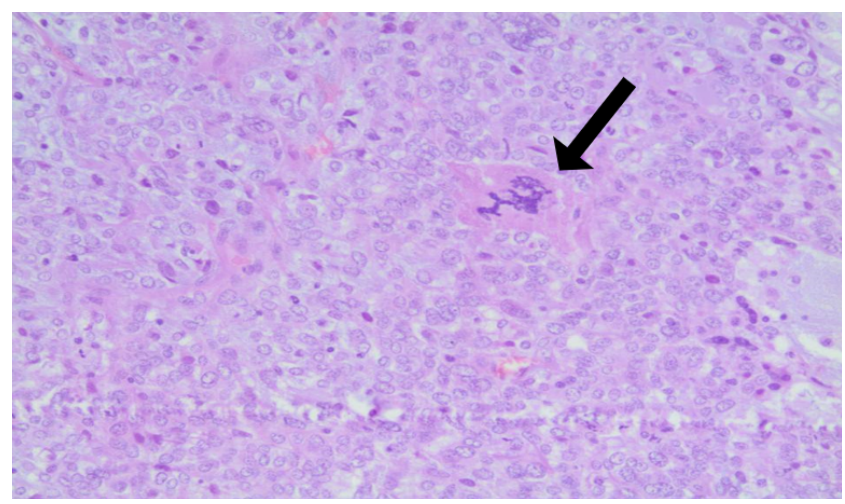

Figure 3. Histopathology of Case 1 (400x magnification): poorly differentiated neoplasm with formation of solid blocks composed of epithelioid cells, with little evident vesicular nuclei and nucleoli. Note the basophilic matrix in the background and an atypical mitosis figure (arrow).

\section{Case 3}

The third case is that of a 59-year-old woman, who presented with a rapidly growing mass in the left breast, measuring $8.7 \mathrm{~cm}$ in the longest axis, classified as BI-RADS 4. The histopathological analysis showed a solid neoplasm composed of epithelioid and rounded cells immersed in a myxochondroid-type stroma (Figure 5). Immunohistochemistry revealed a triple-negative profile, with positivity for CK 5/6, S100 and vimentin, compatible with metaplastic carcinoma with chondroid differentiation. Left axillary sentinel lymph node biopsy did not reveal the presence of lymph node metastasis.

\section{DISCUSSION}

Breast cancer is the most common malignant neoplasm among Western women. In Brazil, the incidence of this neoplasm was expected to reach 66,280 new cases in the year $2020^{8}$, which

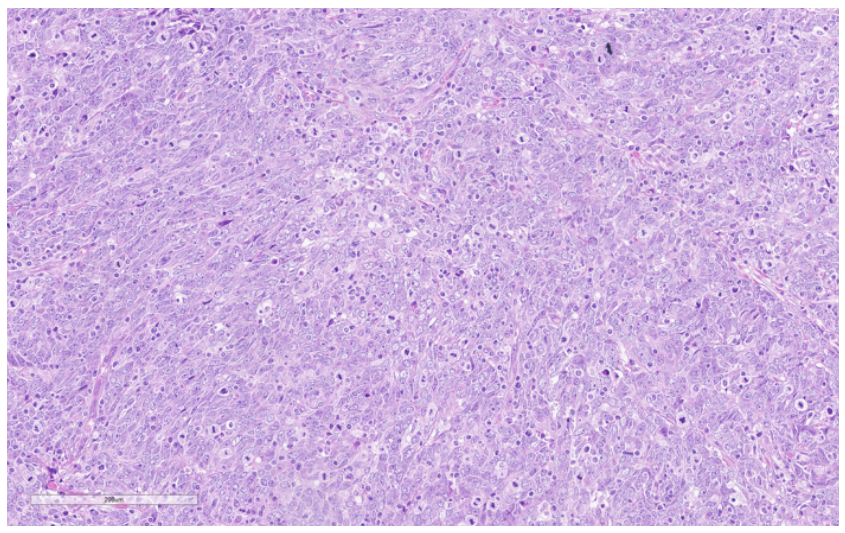

Figure 4. Histopathology of Case 2: neoplastic proliferation composed of spindle cells, arranged in elongated and sometimes intersecting bundles. Presence of vesicular nuclei with little evident nucleoli and numerous mitotic figures.

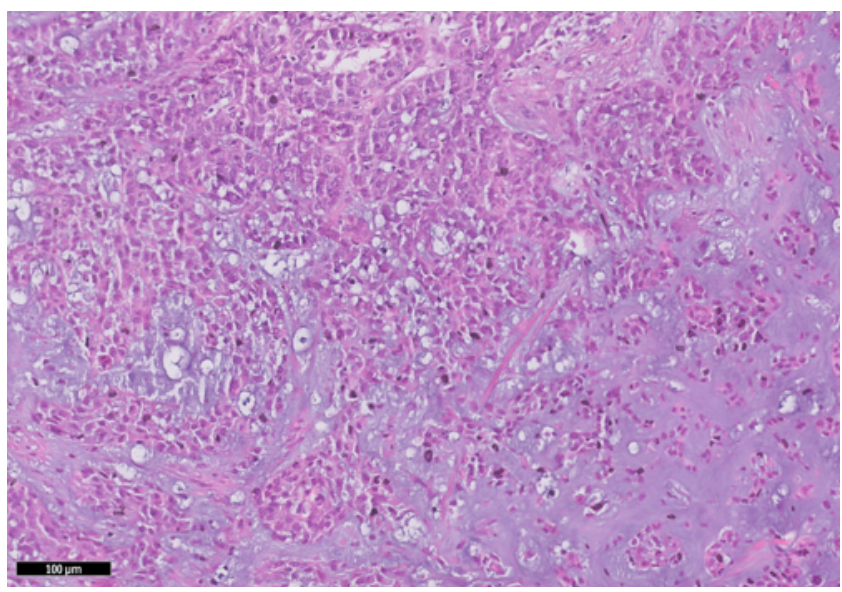

Figure 5. Histopathology of Case 3: solid neoplasm composed of epithelioid and round cells immersed in a myxochondroid-type stroma. Cells have little evident vesicular nuclei and nucleoli. 
represents $29.7 \%$ of the total number of cancer cases in women. In this sense, breast cancer is considered the main cause of female death by cancer in the country, with the exception of non-melanoma skin tumors ${ }^{9}$. The most common histological invasive type of breast cancer is the carcinoma of no special type, formerly known as invasive ductal carcinoma (IDC) (70\%-80\% of cases), followed by invasive lobular carcinoma (ILC) (5\%-15\% of cases), and then by other histological types (medullary carcinoma, papillary carcinoma, metaplastic carcinoma, sarcomas) ${ }^{8}$.

As for the gene expression evaluated by the immunohistochemical study of the ER, PR, and HER2 markers, four cancer subtypes are defined: luminal A (ER+ and/or PR+, HER2 negative and Ki-67 < 14\%); luminal B (ER+ and/or PR+, positive HER2 and Ki-67 $\geq 14 \%$ ); triple-negative or basal (ER-, PR-, HER2 negative) and overexpressed HER2 (ER-, PR-, HER2 positive). The most prevalent subtype described in the literature is luminal A, followed, respectively, by triple-negative, luminal B, and finally, overexpressed HER $2^{10}$. Within the triple-negative group is the basal-like (basaloid) subtype, which expresses basal cytokeratins, such as CK 5/6. Basal-like breast carcinoma shows a more reserved prognostic pattern and several studies have associated it with lower disease-free survival and lower overall survival, when compared to other subtypes ${ }^{6,7,11-13}$. This subtype often presents complex genomic rearrangements and TP53 mutation ${ }^{14-16}$, and has a strong association with mutations in the breast cancer gene 1 (BRCA1 $)^{7,17}$. Morphologically, this subtype is characterized by high histological grade, high mitotic index, presence of areas of central necrosis and prominent inflammatory infiltrate ${ }^{12,13}$. Studies show the presence of high nuclear grade, preponderance of tumor size between 2 and $5 \mathrm{~cm}$ and invasive ductal carcinoma as the most common histological type ${ }^{18}$.

The first case reported here was $4.8 \mathrm{~cm}$ in size and, microscopically, it was a metaplastic carcinoma with epithelioid cells, vesicular pleomorphic nuclei and presence of basophilic matrix in the background, numerous atypical mitosis figures and triple negative immunohistochemical profile, with expression of CK 5/6.

The second case reported is a metaplastic spindle cell carcinoma, which is a very rare neoplasm and represents only $0.1 \%$ of all breast cancers ${ }^{19}$. This is a more aggressive variant of metaplastic carcinoma, characterized by highly atypical spindle cells, with areas of necrosis and evident mitotic figures ${ }^{20}$. According to studies by Khan et al. ${ }^{20}$, metaplastic spindle cell carcinoma is clinically more common in postmenopausal women, manifesting in patients with a mean age of 55 years and presenting with a large and palpable mass (greater than T3 in $50 \%$ of cases), presenting as an oval-shaped mass, with circumscribed margins and a slightly high density, classified as BI-RADS 4 or BI-RADS 5. In the case reported, the patient was 50 years old, has a tumor of $3.9 \mathrm{~cm}$, staged as T2 and with BI-RADS 5 mammographic classification.
Microscopic examination of this type of tumor reveals an infiltrative proliferation of spindle cells with atypia and mitosis, which usually shows epithelial differentiation on immunohistochemical study, exemplified by the expression of $\mathrm{CKs}^{21,22}$. The histological pattern of the second case shows neoplastic proliferation composed of spindle cells, arranged in elongated bundles, which sometimes intersect, and with numerous mitotic figures. The differential diagnosis of metaplastic spindle cell carcinoma can be a malignant phylloid tumor and primary breast sarcomas. Phylloid tumors are negative for $\mathrm{p} 63$ and high molecular weight $\mathrm{CK}$, whereas fusiform metaplastic carcinoma tends to be positive for both ${ }^{23}$. On the other hand, primary breast sarcomas do not show a morphological epithelial component or expression of CKs on immunohistochemical examination ${ }^{23}$.

Immunohistochemistry is the key test that allows for a more accurate diagnosis. Fusiform metaplastic carcinoma is typically a triple-negative tumor, according to studies by Moten et al. ${ }^{24}$, in which 286 cases are evaluated (from 1992 to 2011), with only $15 \%$ being positive for ER, showing the preponderance of triple-negative tumors. There are specific markers with high sensitivity and specificity for spindle cells, which are useful for diagnosis. Focal positivity findings for cytokeratin (AE1/AE3, CK 5/6, CK 7, and CK 14) and the presence of the S100 protein favor this type of neoplasia. There may be a positive reaction to muscle markers such as calponin and smooth muscle actin (SMA $)^{25,26}$, with p63 being a sensitive and relatively specific marker for epithelial cells ${ }^{27,28}$. In the case described, the patient was positive for AE1/AE3, CK 14, CK 7, S100, and AML and negative for CK 5/6, p63 and for ER, PR, and HER2 (triple negative).

The third case reported is a metaplastic carcinoma with chondroid differentiation, measuring $8.7 \mathrm{~cm}$, classified as BI-RADS 4. Metaplastic breast carcinoma (MBC), as already mentioned, is an uncommon type of invasive breast carcinoma, and the chondroid differentiation is even more rare. Chondroid metaplastic carcinoma is known as matrix-producing carcinoma. Epithelial cells show a triple negative pattern and exhibit a high rate of cell proliferation (Ki-67), as reported in the case series by Gwin et al. ${ }^{18}$ and other similar studies ${ }^{29-31}$. Chondroid cells exhibit a positive reaction for pancytokeratin (AE1/AE3) and S100, and a negative reaction for epithelial membrane antigen (EMA). Studies by Kim et al. ${ }^{32}$ reported p53 overexpression in approximately $20 \%$ to $40 \%$ of conventional breast carcinoma cells and p53 overexpression in more than $60 \%$ of epithelial and chondroid cells in metaplastic breast carcinoma ${ }^{32}$. Metaplastic breast carcinomas with chondroid differentiation have a better prognosis than other subtypes ${ }^{6}$. In the case described here, immunohistochemistry revealed that it was a triple-negative tumor (RE, RP, and HER2), with positivity for CK 5/6, Ki67, S100, and vimentin. 
The three cases reported presented nodules between 3.9 and $8.7 \mathrm{~cm}$ - the range of metaplastic breast carcinomas is usually 2 to more than $10 \mathrm{~cm}$ - and showed a histological pattern of cells with little evident vesicular nuclei and nucleoli. The BI-RADS classification of the presented mammograms were 4 and 5, being indicative of high risk for cancer. Regarding the immunohistochemical profile, there were similarities between the three cases described, with absence of expression of hormone receptors and HER2, configuring a triple-negative subtype (typical of metaplastic breast carcinomas). In addition, there was positivity for EGFR, vimentin,
CK 5/6, and p63 associated with a high cell proliferation index (Ki-67) (Figure 6).

According to the analysis of the articles selected for review, it is possible to observe that most of these tumors have a shorter survival and a worse prognosis compared to the other subtypes, and their main therapy of choice is total mastectomy, axillary approach, adjuvant chemotherapy, and radiotherapy (Table 1) 3- $^{3-}$ $5,20,23,28-30$, treatments that were performed on the patients in question. However, as it is a rare and aggressive breast carcinoma subtype, two of the patients died, and another is disease-free, with a 2-year follow-up.
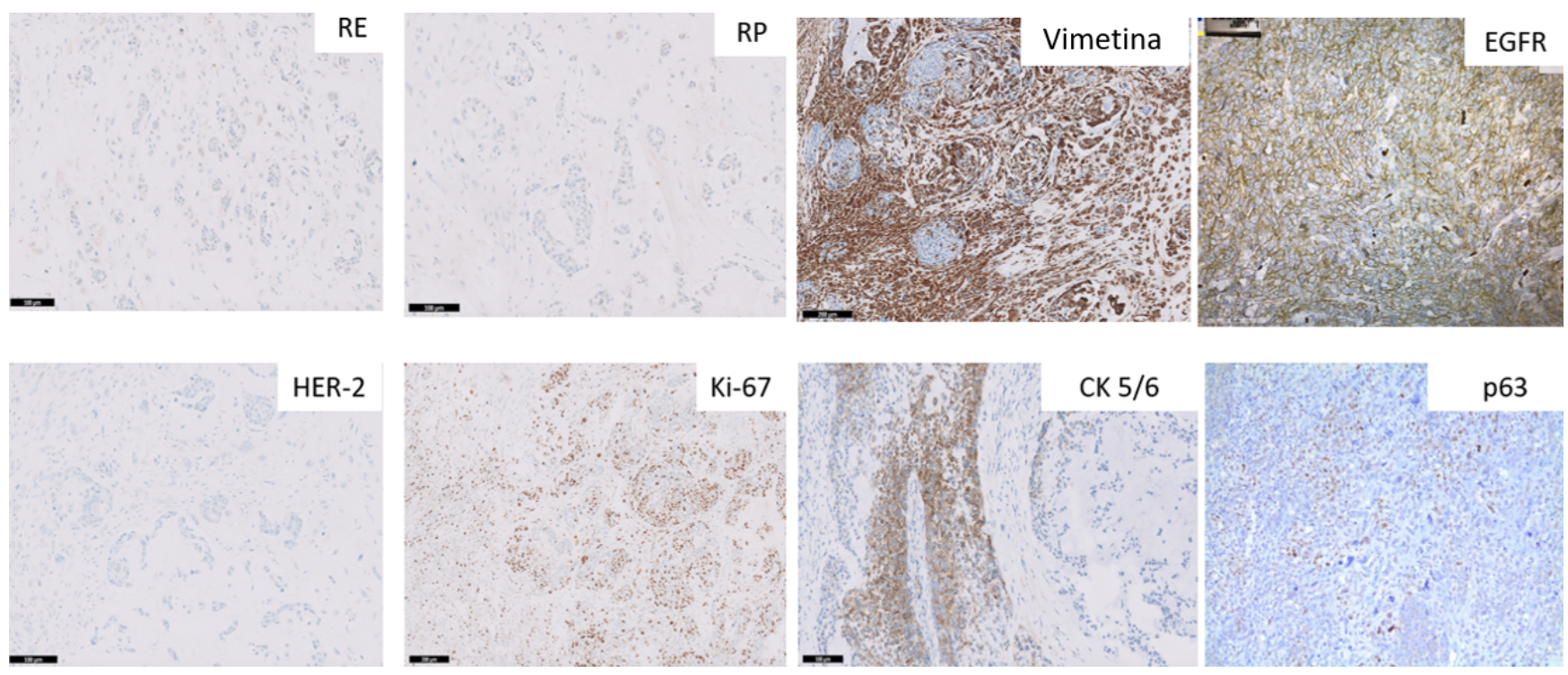

Figure 6. Immunohistochemical profile of reported cases: immunohistochemistry tests were positive for vimetine, EGFR, Ki-67, CK 5/6 and p63 and negative for ER, RP and HER-2 (triple negative).

Table 1. Summary of relevant data from the reviewed works regarding radiological findings, adopted treatment, and prognostic data.

\begin{tabular}{|c|c|c|c|c|}
\hline Studies & Year of publication & Sample (N) & Design & Outcome \\
\hline Han et al. ${ }^{3}$ & 2019 & 97 & Case study & $\begin{array}{l}\text { Matrix-producing tumors achieve better response } \\
\text { to chemotherapy. However, this is not indicative of a } \\
\text { survival advantage. } \\
\text { MBC prognosis and predictive factors: } \\
\text { further studies are needed. }\end{array}$ \\
\hline $\begin{array}{l}\text { El Zein } \\
\text { et al. }{ }^{4}\end{array}$ & 2017 & 554 & $\begin{array}{l}\text { Systematic } \\
\text { review and } \\
\text { Literature } \\
\text { review. }\end{array}$ & $\begin{array}{l}\text { Survival: MBC had fewer fully cured and overall survivors } \\
\text { when compared to patients with TNBC. } \\
\text { Prognosis: MBC has worse long-term clinical outcomes. } \\
\text { Treatment: patients with MBC tended to receive } \\
\text { mastectomy and chemotherapy more frequently } \\
\text { than those with TNBC, while the latter received more } \\
\text { radiotherapy. This difference in treatment may be a direct } \\
\text { product of the MBC being at a higher stage compared to } \\
\text { the TNBC. }\end{array}$ \\
\hline $\begin{array}{l}\text { McKinnon } \\
\text { and Xiao }\end{array}$ & 2015 & $(-)$ & $\begin{array}{l}\text { Literature } \\
\text { review }\end{array}$ & $\begin{array}{l}\text { MMG: MBC can mimic IDC and benign lesions. } \\
\text { Treatment: depends on the size and number of } \\
\text { axillary lymph nodes. There is evidence that associated } \\
\text { radiotherapy promotes benefits. }\end{array}$ \\
\hline
\end{tabular}


Table 1. Continuation.

\begin{tabular}{|c|c|c|c|c|}
\hline Studies & Year of publication & Sample (N) & Design & Outcome \\
\hline Khan et al. ${ }^{20}$ & 2003 & 19 & Case series & $\begin{array}{l}\text { SC x-ray: large mass is the only suggestive finding. } \\
\text { Average tumor size: } 53 \mathrm{~mm} \text {. } \\
\text { All tumors were ER and PR negative, } \\
\text { limiting therapeutic options. } \\
\text { Nottingham Prognostic Index: } 5.2 \\
\text { Primary treatment: surgery (89\%) - total mastectomy and } \\
\text { partial mastectomy. } \\
\text { Survival: } 3.2 \% \text { mortality, with an average of } 18 \text { months. }\end{array}$ \\
\hline Chu et al..$^{23}$ & 2014 & 117 & Cohort & $\begin{array}{l}\text { Prognosis: Triple negative and HER2 positive MBC have a } \\
\text { worse clinical outcome. } \\
\text { Treatment: } \\
\text { - There was no difference between surgical treatment, } \\
\text { adjuvant chemotherapy, hormonal therapy, and } \\
\text { adjuvant radiotherapy. } \\
\text { - The percentage of adjuvant radiotherapy in triple negative } \\
\text { was higher than in HER2 and luminal due to the larger } \\
\text { tumor size, positive lymph nodes and the possibility of later } \\
\text { conservative therapy. }\end{array}$ \\
\hline $\begin{array}{l}\text { Moten } \\
\text { et al. }{ }^{24}\end{array}$ & 2016 & 286 & $\begin{array}{l}\text { Systematic } \\
\text { review }\end{array}$ & $\begin{array}{l}\text { Treatment for spindle cell carcinoma: } \\
\text { - Partial mastectomy (38\%). } \\
\text { - Total mastectomy (55.5\%). } \\
\text { - Radiotherapy in 1/3 of patients. } \\
\text { 10-year survival: } \\
\text { - Stages I and II: } \\
\text {. Partial mastectomy: } 83.9 \% \text {. } \\
\text {. Partial mastectomy + radiotherapy: } 86.7 \% \text {. } \\
\text {. Total mastectomy: } 71.6 \% \text {. } \\
\text { Three-Year Survival: } \\
\text {-Stages III and IV: } \\
\text { - Total mastectomy: } 40 \% \text {. } \\
\text {. Total mastectomy + radiotherapy: } 0 \% \text {. }\end{array}$ \\
\hline Cho et al. ${ }^{25}$ & 2014 & 1 & $\begin{array}{l}\text { Case report and } \\
\text { literature review }\end{array}$ & $\begin{array}{l}\text { SCC: } \\
\text { Radiographic characteristics: oval mass with circumscribed } \\
\text { and slightly hyperdense margins, BI-RADS } 4 \text { or } 5 . \\
\text { Microcalcifications on mammography are uncommon. } \\
\text { Prognosis: uncertain - most important factors: } \\
\text { size and grade. } \\
\text { - Presence of p53 and p63 is associated with potentially high } \\
\text { risk of malignancy and worse prognosis. } \\
\text { Five-year survival: } 28-68 \% \text {. } \\
\text { Treatment: limited, as they are typically triple-negative. } \\
\text { There is no specific treatment established. }\end{array}$ \\
\hline Zhu et al. ${ }^{28}$ & 2017 & 19 & $\begin{array}{l}\text { Systematic } \\
\text { review }\end{array}$ & $\begin{array}{l}\text { - Axillary lymph node metastasis in spindle cell MBC was less } \\
\text { frequent than in IDC, as well as the expression of ER, PR, } \\
\text { and HER2. } \\
\text { Treatment: } \\
\text { - It was noted that axillary dissection should not be done } \\
\text { for breast sarcomas and sarcomas smaller than } 5 \mathrm{~cm} \\
\text { required chemotherapy. } \\
\text { - The surgery of resection of several foci together } \\
\text { with postoperative radiotherapy proved to be more } \\
\text { favorable for MBC of spindle cells of medium and } \\
\text { high degree of differentiation, when compared to the } \\
\text { conventional treatment. }\end{array}$ \\
\hline Song et al. ${ }^{29}$ & 2013 & $55+767$ & $\begin{array}{l}\text { Systematic } \\
\text { review }\end{array}$ & $\begin{array}{l}\text { Prognosis: } \\
\text { - MBC has a worse prognosis than IDC and TN-IDC. } \\
\text { - Factors with worse prognosis of MBC: tumor > } 5 \text { cm, } \\
\text { presence of lymph nodes and Ki- } 67^{3} 14 \% \text {. } \\
\text { Five-year survival rate: } \\
\text { - MBC: } 54.5 \% . \\
\text { - IDC: } 85.1 \% \text {. } \\
\text { - TN-IDC: } 73.3 \% \text {. } \\
\text { Five-year disease-free survival rate: } \\
\text { - MBC: } 45.5 \% . \\
\text { - IDC: } 71.2 \% \text {. } \\
\text { - TN-IDC: } 60.3 \% \text {. }\end{array}$ \\
\hline
\end{tabular}


Table 1. Continuation.

\begin{tabular}{|c|c|c|c|c|}
\hline Studies & Year of publication & Sample (N) & Design & Outcome \\
\hline $\begin{array}{l}\text { Schwartz } \\
\text { et al. }{ }^{30}\end{array}$ & 2013 & $(-)$ & $\begin{array}{l}\text { Literature } \\
\text { review }\end{array}$ & $\begin{array}{l}\text { MBC radiographic characteristics: } \\
\text { - Mammography: high density, circumscribed/obscure/ } \\
\text { irregular and/or spiculated margins. Generally without } \\
\text { calcifications. Round or oval shapes with circumscribed } \\
\text { margins have a more benign appearance. } \\
\text { - Ultrasonography: heterogeneous or hyperechoic solid or } \\
\text { mixed mass. } \\
\text { Treatment: } \\
\text { - Response to chemotherapy in MBC (16.7\%) is lower than in } \\
\text { IDC ( } 21-75 \%) \text {. } \\
\text { - Neoadjuvant chemotherapy: minimally effective for MBC, } \\
\text { with tumor shrinkage and progression prevention. } \\
\text { Prognosis: worse overall prognosis compared to other } \\
\text { standard invasive breast cancers. }\end{array}$ \\
\hline
\end{tabular}

MBC: metaplastic breast carcinoma; TNBC: triple negative breast cancer; SC: spinocellular carcinoma; IDC: invasive ductal carcinoma; SCC: squamous cell carcinoma; TN-IDC: triple negative invasive ductal carcinoma; Nottingham Prognostic Index: used to determine prognosis after breast cancer surgery. It uses three criteria: tumor size, number of lymph nodes involved, and tumor grade; HER2: human epidermal growth factor - receptor 2.

\section{CONCLUSION}

Three cases have been described as an extremely rare and aggressive type of tumor, usually classified radiologically as BI-RADS 4 and 5. Immunohistochemistry is an essential test for an accurate diagnosis of metaplastic breast carcinoma, and the three cases reported present triple-negative phenotype, which is a typical feature of this tumor. This exam is also able to differentiate similar tumors and identify the predominant cell type, which directly influences prognosis and treatment. Prognosis is related to staging, size, distant and lymph node metastasis, and most of these tumors have shorter survival and worse prognosis compared to other subtypes. Most of them have mastectomy as the treatment of choice, with an axillary approach, adjuvant chemotherapy and radiotherapy.
However, due to the rarity of this histological type, there are insufficient data and guidelines for optimal treatment, and information about therapy is based on small retrospective studies rather than randomized studies. In this sense, further studies will be needed to determine a gold standard and personalized therapy for this disease.

\section{AUTHORS' CONTRIBUTIONS}

G.P.: Investigation, Methodology, Writing - original draft.

C.F.F.: Investigation, Methodology, Writing - original draft.

L.D.: Investigation, Methodology, Writing - original draft.

K.C.K.P.: Conceptualization, Data curation, Formal analysis, Project administration, Supervision, Writing - review \& editing.

\section{REFERENCES}

1. Reis-Filho JS, Gobbi H, McCart Reed AE, Rakha EA, Shin SJ, Sortiriou $\mathrm{C}$, et al. WHO classification of tumours: breast tumours. $5^{\mathrm{a}}$ ed. Geneva: WHO; 2020.

2. Lakhani SR, International Agency for Research on Cancer, World Health Organization. WHO classification of tumours of the breast: views of a working group that convened for a consensus and editorial meeting at the International Agency for Research on Cancer (IARC), Lyon, September 1 - 3, 2011. 4. ed. Lyon: Agency for Research on Cancer; 2012. 240 p.

3. Han M, Salamat A, Zhu L, Zhang H, Clark BZ, Dabbs DJ, et al. Metaplastic breast carcinoma: a clinical-pathologic study of 97 cases with subset analysis of response to neoadjuvant chemotherapy. Mod Pathol. 2019;32(6):807-16. https://doi. org/10.1038/s41379-019-0208-x

4. El Zein D, Hughes M, Kumar S, Peng X, Oyasiji T, Jabbour H, et al. Metaplastic carcinoma of the breast is more aggressive than triple-negative breast cancer: a study from a single institution and review of literature. Clin Breast Cancer. 2017;17(5):382-91. https://doi.org/10.1016/j.clbc.2017.04.009
5. McKinnon E, Xiao P. Metaplastic carcinoma of the breast. Arch Pathol Lab Med. 2015;139(6):819-22. https://doi.org/10.5858/ arpa.2013-0358-rs

6. Shin HJ, Kim HH, Kim SM, Kim DB, Kim M-J, Gong G, et al. Imaging features of metaplastic carcinoma with chondroid differentiation of the breast. Am J Roentgenol. 2007;188(3):6916. https://doi.org/10.2214/ajr.05.0831

7. Nielsen TO, Hsu FD, Jensen K, Cheang M, Karaca G, Hu Z, et al. Immunohistochemical and clinical characterization of the basal-like subtype of invasive breast carcinoma. Clin Cancer Res. 2004;10(16):5367-74. https://doi.org/10.1158/1078-0432.ccr-04-0220

8. Instituto Nacional de Câncer José Alencar Gomes da Silva (INCA). Brasil: estimativas de novos casos. Brasil: Ministério da Saúde; 2020.

9. Ferlay J, Shin H-R, Bray F, Forman D, Mathers C, Parkin DM. Estimates of worldwide burden of cancer in 2008: GLOBOCAN 2008. Int J Cancer. 2010;127(12):2893-917. https://doi. org/10.1002/ijc.25516 
10. Sarturi PR, Cunha-Junior AD, Morais CF. Perfil imunohistoquímico do câncer de mama de pacientes atendidas no hospital de câncer Cascavel - Paraná. Rev Bras Oncol Clín. 2012;8(29):121-4.

11. Sorlie T, Tibshirani R, Parker J, Hastie T, Marron JS, Nobel A, et al. Repeated observation of breast tumor subtypes in independent gene expression data sets. Proc Natl Acad Sci. 2003;100(14):8418-23. https://doi.org/10.1073/pnas.0932692100

12. Carey LA, Perou CM, Livasy CA, Dressler LG, Cowan D, Conway K, et al. Race, breast cancer subtypes, and survival in the Carolina Breast Cancer Study. JAMA. 2006;295(21):2492502. https://doi.org/10.1001/jama.295.21.2492

13. Cirqueira MB, Moreira MAR, Soares LR, Freitas-Júnior R. Subtipos moleculares do câncer de mama. Femina. 2011;39(10):499-503.

14. Russnes HG, Vollan HKM, Lingjaerde OC, Krasnitz A, Lundin P, Naume B, et al. Genomic architecture characterizes tumor progression paths and fate in breast cancer patients. Sci Transl Med. 2010;2(38):38ra47. https://doi.org/10.1126/ scitranslmed.3000611

15. Sørlie T. Molecular classification of breast tumors: toward improved diagnostics and treatments. Methods Mol Biol. 2007;360:91-114. In: Target Discovery and Validation Reviews and Protocols. New Jersey: Humana Press; 2006. p. 91-114. https://doi.org/10.1385/1-59745-165-7:91

16. Kwei KA, Kung Y, Salari K, Holcomb IN, Pollack JR. Genomic instability in breast cancer: Pathogenesis and clinical implications. Mol Oncol. 2010;4(3):255-66. https://doi. org/10.1016/j.molonc.2010.04.001

17. Foulkes WD, Stefansson IM, Chappuis PO, Bégin LR, Goffin JR, Wong N, et al. Germline BRCA1 mutations and a basal epithelial phenotype in breast cancer. J Natl Cancer Inst. 2003;95(19):1482-5. https://doi.org/10.1093/jnci/djg050

18. Gwin K, Wheeler DT, Bossuyt V, Tavassoli FA. Breast carcinoma with chondroid differentiation: a clinicopathologic study of 21 triple negative (ER-, PR-, Her2/neu-) cases. Int J Surg Pathol. 2010;18(1):27-35. https://doi.org/10.1177/1066896909332732

19. McMullen ER, Zoumberos NA, Kleer CG. Metaplastic breast carcinoma: update on histopathology and molecular alterations. Arch Pathol Lab Med. 2019;143(12):1492-6. https:// doi.org/10.5858/arpa.2019-0396-ra

20. Khan HN, Wyld L, Dunne B, Lee AHS, Pinder SE, Evans AJ, et al. Spindle cell carcinoma of the breast: a case series of a rare histological subtype. Eur J Surg Oncol. 2003;29(7):600-3. https://doi.org/10.1016/s0748-7983(03)00107-0
21. Rungta S, Kleer CG. Metaplastic carcinomas of the breast: diagnostic challenges and new translational insights. Arch Pathol Lab Med. 2012;136(8):896-900. https://doi.org/10.5858/ arpa.2012-0166-cr

22. Abd El-All HS. Breast spindle cell tumours: about eight cases. Diagn Pathol. 2006;1:13. https://doi.org/10.1186/1746-1596-1-13

23. Chu Z, Lin H, Liang X, Huang R, Zhan Q, Jiang J, et al. Clinicopathologic characteristics of typical medullary breast carcinoma: a retrospective study of 117 cases. PLoS One. 2014;9(11):e111493. https://doi.org/10.1371/journal.pone.0111493

24. Moten AS, Jayarajan SN, Willis AI. Spindle cell carcinoma of the breast: a comprehensive analysis. Am J Surg. 2016;211(4):71621. https://doi.org/10.1016/j.amjsurg.2015.11.023

25. Cho SN, Kim YS, Kim KC. Very rare case of spindle cell carcinoma of breast in male. J Breast Dis. 2014;2(2):69-72. https://doi.org/10.14449/jbd.2014.2.69

26. Ünal B, Erdoğan G, Karaveli FŞ. Step by step approach to rare breast lesions containing spindle cells. Springerplus. 2015;4:678. https://doi.org/10.1186/s40064-015-1480-y

27. Koker MM, Kleer CG. p63 expression in breast cancer: a highly sensitive and specific marker of metaplastic carcinoma. Am J Surg Pathol. 2004;28(11):1506-12. https://doi.org/10.1097/01. pas.0000138183.97366.fd

28. Zhu H, Li K, Dong D, Fu J, Liu D, Wang L, et al. Spindle cell metaplastic carcinoma of breast: a clinicopathological and immunohistochemical analysis: histopathology of SpCMC. Asia Pac J Clin Oncol. 2017;13(2):e72-8. https://doi.org/10.1111/ ajco. 12322

29. Song Y, Liu X, Zhang G, Song H, Ren Y, He X, et al. Unique clinicopathological features of metaplastic breast carcinoma compared with invasive ductal carcinoma and poor prognostic indicators. World J Surg Oncol. 2013;11:129. https://dx.doi. org/10.1186\%2F1477-7819-11-129

30. Schwartz TL, Mogal H, Papageorgiou C, Veerapong J, Hsueh EC. Metaplastic breast cancer: histologic characteristics, prognostic factors and systemic treatment strategies. Exp Hematol Oncol. 2013;2(1):31. https://doi.org/10.1186/2162-3619-2-31

31. Edenfield J, Schammel C, Collins J, Schammel D, Edenfield WJ. Metaplastic breast cancer: molecular typing and identification of potential targeted therapies at a single institution. Clin Breast Cancer. 2017;17(1):el-10. https://doi.org/10.1016/j.clbc.2016.07.004

32. Kim Y-J, Shim H-S, Lee H, Jung W-H. Metaplastic carcinoma with extensive chondroid differentiation in the breast (chondroid carcinoma). Yonsei Med J. 2006;47(2):259-63. https://dx.doi.org/10.3349\%2Fymj.2006.47.2.259 